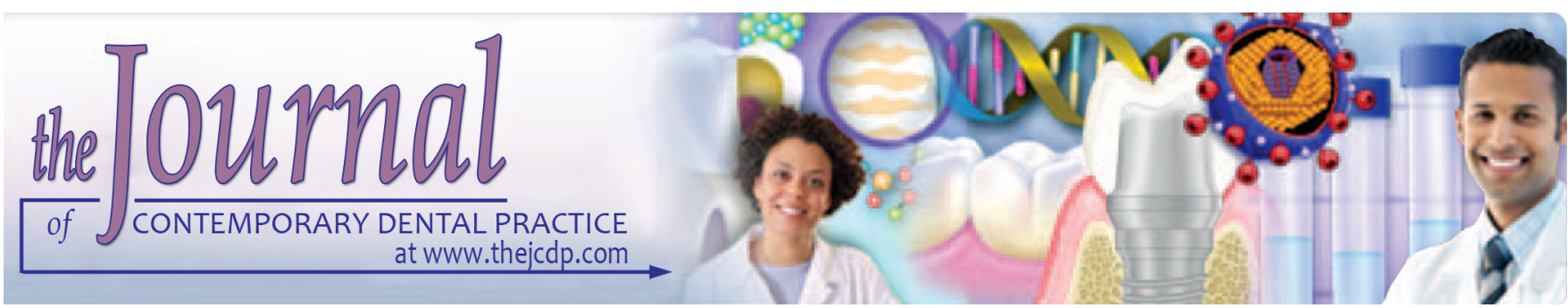

\title{
Cement AH Plus Adhesiveness Assessment Associated with Mineral Trioxide Aggregate in Different Proportions (Push-out Test)
}

\author{
${ }^{1}$ Carlos AM Falcão, ${ }^{2}$ Elayne MO de Lima, ${ }^{3}$ José D de M Júnior, ${ }^{4}$ Sérgio AP Freitas, ${ }^{5}$ Eduardo $S$ de L Veras, \\ ${ }^{6}$ Luana KB Moura, ${ }^{7}$ Lucas F Falcão
}

\begin{abstract}
Aim: The aim of the study is to evaluate the adhesiveness of the AH Plus plug cement, plus the mineral trioxide aggregate (MTA) in different proportions, through the push-out test.

Materials and methods: The authors utilized fifty premolars with a single conduit, which were divided into five groups with 10 teeth. In group 1, the authors performed an obturation with $\mathrm{AH}$ Plus cement, group 2 was filled with $\mathrm{AH}$ Plus cement with $10 \%$ of MTA, group 3 was filled with AH Plus cement plus $20 \%$ MTA, group 4 was filled with AH Plus with $30 \%$ of MTA and group 5 filling was performed with the MTA Fillapex endodontic cement. The specimens were sectioned in $2 \mathrm{~mm}$ slices and submitted to the push-out test in a universal testing machine. The authors cataloged the data and follow through with statistical analysis based on T-test for independent samples, with a significance level of $5 \%$.
\end{abstract}

Results: There was no statistical difference in group 2. Groups 3 and 4 presented better adhesion than $\mathrm{AH}$ Plus cement and MTA Fillapex. There was no statistical difference between the AH Plus cement and the MTA Fillapex.

Conclusion: The authors concluded that the addition of MTA in the proportion of $10 \%$ to the $\mathrm{AH}$ Plus does not alter its adhesive

\footnotetext{
${ }^{1}$ Department of Endodontics, Uninovafapi University Center, Piauí, Brasil

2,3,7 Department of the Dentistry, University Center Uninovafapi, Piauí. Brasil

${ }^{4}$ Department of Radiology and Imaginology at the University Center Uninovafapi.Piauí. Brasil. Email:sergioxray@hotmail. com

${ }^{5}$ Department of Periodontics, Uninovafapi University Center, Piauí, Brasil

${ }^{6}$ Department of Endodontics, Oral Pathology Uninovafapi University Center, Piauí, Brasil
}

Correponding Author: Carlos AM Falcão, Department of Endodontics, Uninovafapi University Center, Piauí, Brasil, Phone: (086) 2106-0700, e-mail: cfalcao@novafapi.com.br property. They also observed that when the MTA increased by $20 \%$ and $30 \%$ there was an increase in the adhesiveness of the material when submitted to the push-out test.

Clinical significance: The relevance of this study refers to the MTA inducing the deposition of mineralized tissue. However, it is necessary to compare it to the AH Plus cement considered "Gold Standard" in physical-chemical properties tests.

Keywords: Adhesion, Dental cement, Dentistry.

How to cite this article: Falcão CAM, Lima EMO, Júnior JDM, Freitas SAP, Veras ESL, Moura LKB, Falcão LF. Cement AH Plus Adhesiveness Assessment Associated with Mineral Trioxide Aggregate in Different Proportions (Push-out Test). J Contemp Dent Pract 2018;19(12):1444-1448.

Source of support: Nil

Conflict of interest: None

\section{INTRODUCTION}

Endodontics is the dentistry specialty responsible for the prevention and treatment of diseases of the dental pulp and the clinical-therapeutical treatment of cases of pulp necrosis and its possible consequences. In general, it consists of the emptying, modeling and obturation of the space previously occupied by the pulp.

\section{Cement AH Plus Adhesiveness Assessment}

Root canal obturation works effectively as a barrier to the return of contamination and infection and, therefore, complements all efforts made in the other stages of endodontic treatment. Thus, for the objectives of this important phase to be achieved, it must be understood that the obturator material assumes a role of extreme importance, mainly in relation to the sealing of the root canal. ${ }^{1}$

It is noticed that one of the great difficulties in the area of endodontic obturator materials is to find the ideal material to be in close contact with the periapical 
tissues without causing any alteration in the performed endodontic treatment.

The AH Plus is a root canal sealant presented in the $\mathrm{A}+\mathrm{B}$ double paste and composed of an epoxy resin polymer. This endodontic cement offers biological compatibility, radiopacity, color stability, easy removal, adequate fluidity with low contraction, solubility and an adhesion strength when compared to other cement. The cement AH Plus still needs to be improved in its biological properties, although in relation to its physical and chemical properties they are among the best already reported. ${ }^{2}$

The MTA has been widely used because it is a very satisfactory material for retrograde obturation, and because it presents appropriate physicochemical and biological properties in several clinical situations, mainly due to its biocompatibility and its osteoinductive action potential and conductive cement. It is a material whose main purpose is to seal communications between the root canal system and the external surfaces of the teeth at all levels, also capable of inducing the deposition of mineralized tissue, preserving pulp vitality, proving efficacy as a capping material. ${ }^{3}$

The MTA presents an unusual property to other dental materials, which is the possibility of being used in the oral environment in the presence of fluids. Its sealing ability explains its indication in the treatment of root and lateral perforations of the pulp chamber in the furcation region, in addition to retrobturation, pulp capping and pulpotomy. ${ }^{4}$

\section{Cement AH Plus Adhesiveness Assessment}

The adhesion strength test has become widely used to determine the effectiveness of adhesion between endodontic materials and tooth structure., 5 The push-out has proven to be effective, reproducible and allows cement to be evaluated even though adhesion strength is low. ${ }^{5}$

The aim of this study is to evaluate the adhesiveness of the AH Plus plug material plus the MTA in different proportions through the push-out test.

\section{MATERIALS AND METHODS}

The authors tested fifty natural teeth with a single conduit, giving preference to the lower premolars obtained through the tooth bank of the university center UNI NOVAFAPI. The teeth were transversely sectioned with a double-sided diamond disc (KG Soresen, Barueri - SP, Brazil) under low speed (Dabi Atlante Ltda, Ribeirão Preto, SP, Brazil) under refrigeration, below the enamel cement junction, in order to standardize the length of roots in $14 \mathrm{~mm}$. The working length was established by inserting a K \#10 file (Dentsply-Maillefer, Ballaigues,
Switzerland) into the canal until its tip was visualized in the apical foramen and recessed $1 \mathrm{~mm}$. On the other hand, teeth with lateralized foramina, in which the actual canal length was less than $13 \mathrm{~mm}$, were replaced.

The biomechanical preparation was performed using the ProTaper Universal rotating system (DentsplyMaillefer, Ballaigües, Switzerland), utilizing the SX instrument for cervical preparation and, in the middle and apical thirds, instruments S1, S2, F1, F2, F3, F4 and F5, which were driven by the X-Smart counter-angle (Dentsply-Maillefer) with continuous rotational speed $300 \mathrm{rpm} / \mathrm{min}$ and $3 \mathrm{~N} / \mathrm{cm}$.

Irrigation was performed at each instrument change with $2 \mathrm{~mL}$ of $1 \% \mathrm{NaOCl}$ using a $10 \mathrm{~mL}$ disposable plastic syringe (Ultradent, South Jordan, Utah, USA) and Navitip needle (Ultradent, South Jordan, Utah, USA). Finally, final irrigation was performed with 17\% EDTA, maintained for 3 minutes inside the root canal, followed by $10 \mathrm{~mL}$ of distilled water.

The root canals were dried with absorbent paper tips (Dentsply-Maillefer, Ballaigües, Switzerland) and the types of cement selected for the study were used. Pure endodontic cementa and other

\section{Cement AH Plus Adhesiveness Assessment}

Endodontic cement was prepared in the same way as for the study of physicochemical properties, with AH Plus cement being used in a ratio of 1:1, MTA Fillapex in a ratio of $1: 1$ and finally cement AH Plus plus $10 \%, 20 \%$ and $30 \%$ of MTA, considering that this percentage of the MTA was obtained with the aid of a precision scale, so that after all weighing they were spatulated until homogeneous consistency.

The teeth were divided into five groups, each group consisting of 10 teeth. In the first group, the obturation was performed with pure AH Plus cement, while the second group was filled with AH Plus cement plus 10\% MTA; the third group was filled with AH Plus cement plus 20\% MTA; the fourth group was obturated with AH Plus plus $30 \%$ MTA, and finally, in the latter group, the obturation was performed with the MTA Fillapex endodontic cement.

The root canals were obturated using the lateral condensation technique. The main gutter cone ProTaper F5 (Dentsply-Maillefer, Ballaigues, Switzerland) was inserted up to the working length and then the digital spacer \# 35 (Dentsply-Maillefer, Ballaigues, Switzerland) was inserted adjacent to the main cone, obtaining space for the insertion of the accessory cones F (DentsplyMaillefer, Petrópolis, RJ, Brazil) of gutta-percha. The excess cones of gutta-percha were cut at the mouth of the root canal with the aid of Hollemback 3S (Duflex, S. S. White dental articles Ltda., Rio de Janeiro, RJ, Brazil) heated. 
After the obturation, the roots were submitted to a machine (IsoMet 1000, precision saw, BUEHLER) to be sectioned and to obtain the slices of the cervical, middle and apical third of the roots, with a thickness of approximately $2 \mathrm{~mm}$ and under running water. Thus, each slice had its measured thickness, larger and smaller diameter in the cervical direction and larger and smaller diameter in the apical direction, with the aid of a digital caliper.

The slices underwent a push-out test on the Instron Universal Instrument Machine 3345 (Instron Corporation, Canton, MA, USA), where each slice was placed on its smaller diameter face so that the

\section{Cement AH Plus Adhesiveness Assessment}

Channel was face up and aligned with a tip of $1.4 \mathrm{~mm}$ and $6 \mathrm{~mm}$ in length, of the machine used to press the cement.

This methodology provides accurate and reproducible alignment of the specimen so that the rod used does not contact the dentin layer when the obturator material is pressed at a velocity of $1 \mathrm{~mm} / \mathrm{min}$. The results of the maximum force, expressed in $\mathrm{K}$ Newton, required for the displacement of the cement were recorded and later converted into Mpa, to be submitted to statistical analysis.

\section{RESULTS}

The values corresponding to the mean and the standard deviation of the adhesiveness measured in Mpa are shown in Table 1 below:

The AH Plus $+10 \%$ presented lower adhesiveness than the AH Plus + 20\% MTA and AH Plus + 30\% MTA (Table 2)

The authors verified that there was no statistical difference when comparing the cement AH Plus + $20 \%$ MTA and AH Plus + 30\% MTA. The AH Plus + $10 \%$ of MTA did not present statistical difference when compared to AH Plus and had greater adhesiveness than the MTA FILLAPEX.

\section{DISCUSSION}

The adhesiveness of endodontic cement represents one of its main characteristics, since it avoids the percolation of fluids between the spaces of the obturation, besides avoiding the

Table 1: Mean and standard deviation of adhesion measurements by cement type and proportion. Teresina (PI), 2017

\begin{tabular}{lll}
\hline & Mean & Standard Deviation \\
\hline AH Plus & 958,68 & 744,73 \\
AH Plus + 10\% MTA & 1130,52 & 564,08 \\
AH Plus + 20\% MTA & 1689,59 & 945,02 \\
AH Plus + 30\% MTA & 1567,78 & 975,26 \\
MTA Fillapex & 662,41 & 770,73 \\
\hline
\end{tabular}

Source: Data processed by the authors

\section{Cement AH plus Adhesiveness Assessment}

Displacement of the obturator mass during the operative procedures. Thus, it becomes fundamental to study the adhesiveness of these cement to gutta-percha cones and the dentinal walls of the root canal. ${ }^{7}$

The lack of specific guidelines from the American Dental Association (ADA) led to the development of a wide range of experimental models and methodologies without standardization. Some variables may interfere with the results of the research and the understanding of the cement adhesive properties to the channel walls, methodology, dentine surface treatment and cement type. ${ }^{8,9}$

The present study chose to utilize the push-out test because of its advantage of being more sensitive to small variations between the specimens and variations in the stress distribution during the application of the load when compared to the tensile test or resistance test to shear bond strength.

The push-out test allows a better evaluation than the conventional shear tests because the fracture occurs parallel to the dentin-cement interface, which makes it a true shear test for parallel-side samples. Its great advantage is to simulate the clinical condition more faithfully. ${ }^{8}$

Cement based on epoxy resin has been widely used because their acceptable physical properties, reduced solubility, good apical sealing ability, and adequate biological performance. The AH plus cement, used as a reference product in many investigations, has these properties, besides a small contraction when compared to other cement. The good performance of this cement, based on epoxy resin, has been related to its high degree of flow and long polymerization time, which results in a greater mechanical locking between cement and root dentin. This fact increases the penetration of the material within micro-irregularities, increasing resistance to removal or displacement, which can be translated as greater adhesion. ${ }^{10}$

\section{Cement AH Plus Adhesiveness Assessment}

Mineral trioxide aggregate (MTA) is a hydrophilic powder mixture consisting of tricalcium silicate, tricalcium oxide,

Table 2: Comparison between groups G1- AH Plus; G2- AH Plus + 10\% MTA; G3- AH Plus + 20\% MTA; G4- AH Plus + 30\% MTA E G5- MTA Fillapex

\begin{tabular}{llllll}
\hline Groups & G1 & G2 & G3 & G4 & G5 \\
\hline G1 & - & 0,329 & $0,002^{*}$ & $0,009^{*}$ & 0,135 \\
G2 & - & - & $0,009^{*}$ & $0,043^{*}$ & $0,001^{*}$ \\
G3 & - & - & - & $0,625^{*}$ & $0,000^{*}$ \\
G4 & - & - & - & - & $0,000^{*}$ \\
G5 & - & - & - & - & - \\
\hline (') indicate significant difference between groups in relation to adhesiveness \\
(p<0,05). \\
Source: Data processed by the authors.
\end{tabular}


silicate oxide, and tricalcium aluminate. Although it does not contain calcium hydroxide after its hardening calcium oxide is formed, which can react with the tissue fluids to produce calcium hydroxide. ${ }^{11}$

The MTA was developed to seal paths of communication between the canal system and the external surface of the tooth. It is a powder that consists of fine hydrophilic particles that harden when they come in contact with water. Hydration of the powder results in a colloidal gel, which solidifies a hard structure. This material is predisposed to extend during the hydration hardening reaction, which is one of the reasons for its excellent sealing ability. ${ }^{12-14}$

The addition of MTA to the AH Plus endodontic cement proposed in the present work aims to add the ability to stimulate hard tissue deposition, thus promoting an ideal biological seal.

The addition of MTA to the AH Plus endodontic cement should be sufficient to improve its biological properties without, however, altering the physical properties, among them, the adhesive capacity. Since, when $20 \%$ and $30 \%$ MTA was added to the AH Plus, there was a significant increase in the adhesive capacity when compared to the AH Plus in the original form. This result is related to the chemical and physical characteristics of cement based on epoxy resin, potentialized by the adhesive properties of the MTA, as previously mentioned.

The addition of $10 \%$ MTA to the AH Plus cement showed similar adhesive strength to the AH Plus in the original form. Probably the small amount of MTA added was not enough to change the adhesiveness of the cement.

The MTA Fillapex cement showed similar adhesive strength to the results obtained with the AH Plus cement corroborating to the studies of Assmann et al. ${ }^{8}$

The present study presented same result, stating that the AH Plus cement did not present a significant adhesion difference when compared to the Fillapex MTA. On the other hand, the association AH Plus + MTA 10\% presented greater adhesion in relation to MTA fillapex due to the potentiation of the adhesive capacity with the addition of the MTA.

\section{Cement AH Plus Adhesiveness Assessment}

The association between 10\% MTA and resin cement AH Plus did not change the adhesive properties of the cement. When $20 \%$ and $30 \%$ of MTA were added, it presented more significant results, besides obtaining better results than the MTA Fillapex cement, which contains MTA in its composition.

\section{CONCLUSION}

Therefore, base on the results obtained and according to the methodology used, it is concluded that:
- The addition of $10 \%$ MTA to the AH Plus does not change the adhesive property of the AH Plus.

- When the MTA was added in $20 \%$ and $30 \%$ there was an increase in the adhesiveness of the material when subjected to the push-out test.

- AH Plus + 10\% MTA cement showed better adhesive strength than a cement containing MTA in its composition.

\section{REFERENCES}

1. Bueno CES, Pelegrine RA, Silveira CFM, Bueno VCPS, Alves, Cunha VORS, Pereira GDS, Paulillo LAMS. The impact of endodontic irrigating solutions on the push-out shear bond strength of glass fiber posts luted with resin cements. General Dentistry, 2016;64(1):26-30.

2. Reiss-Araujo C, Araújo SS, Baratto FF, Carvalho LR, Fidel SR. Comparação da infiltração apical entre os cimentos obturadores AH Plus, Sealapex, Sealer 26 e Endofill por meio da diafanização. RSBO Revista Sul-Brasileira de Odontologia, 2009;6(1):21-28.

3. Gomes-Filho JE, Rodrigues G, WatanabeS, Bernabe PFE, Lodi CS, Gomes AC, Faria MD, Santos AD, Moraes JCS. Evaluation of the Tissue Reaction to Fast Endodontic Cement (CER) and Angelus MTA. J Endod. 2009; 35(10):1377-1380.

4. Chang SW, Bae WJ, Lee JK Yi, S, Lee DW, Kum KY, Kim EC. Odontoblastic Differentiation, Inflammatory Response, and Angiogenic Potential of 4 Calcium Silicate-based Cements: Micromega MTA, ProRoot MTA, etroMTA, and Experimental Calcium Silicate Cement. J Endod. 2015;41(9):1524-1529.

5. Ungor M, Onay EO, Orucoglu H. Push-out Bond strengths: the Epiphany-resilon endodontic obturation system compared with different pairings of Epiphany, Resilon, AH Plus and gutta-percha.Int Endod J. 2006;39(8):643-47.

6. Huffman BP, Mai S, Pinna L, Weller RN, Primus CM, Gutmann Jl, et al. Dislocation resistance of ProRoot Endo Sealer, a calcium silicate-based root canal sealer, from radicular dentine. Int Endod J. 2009;42(1):34-46.

7. Sousa-Neto, MD.; Passarinho-Neto, JG.; Carvalho-Junior, JR, Cruzfilho, AM, Pécora, JD, Saquy PC. Evaluation of the effect of EDTAC, EGTACand CDTA on dentin adhesiveness and microleakage with root canal sealers. Braz. Dent. J., 2002, 13: 123-128.

8. Assmann E, Scarparo RK, Bottcher DE, Grecca FS. Dentin bond strength of two mineral trioxide aggregate-based and one epoxy resin-based sealers. J Endod. 2012;38(2):219-221.

9. NUNES, V H et al. Adhesion of Epiphany and AH Plus sealers to human root dentin treated with different solutions. Braz. Dent. J.; 2008;19(1):46-50.

10. Casanova VS. Influence of chemical auxiliaries on the resistance to displacement of ah plus to root dentin. Federal University of Rio Grande do Sul, Faculty of Dentistry, completion work of dentistry course. Porto alegre, 2010.

11. Mota CCBDO, Brasil CDMV, Carvalho NRD, Beatrice LCD, Teixeira HM, Nascimento ABLD, Silva CHV. Properties and biological aspects of aggregate mineral trioxide: review and literature. Rev Odontol UNESP. 2010;39(1):49-54.

12. Chakmakchi M, Karoni C, Meliou H, Kerezoudis NP. Sealing effectiveness of white ProRoot MTA in furcation perforations. Int. Endod J. 2003; 36(12): 929-930. 
13- Fridland M, Rosado R. Mineral trioxide aggregate (MTA) Solubility and porosity with different water-to-powder ratios. J Endod. 2003; 29(12):814-817.
14. Correia V. Aggregate mineral trioxide and its use in pediatric dentistry. [dissertation]. Porto. Faculty of Dental Medicine. University of Porto. 2010. 